\title{
Sobre territórios, limites e relações físicas e visuais no aterro da Baía Sul em Florianópolis, SC.
}

About territories, boundaires and physical and visual relations at Baia Sul landfill in Florianopolis, SC.

\author{
Luiza Helena Ferraro*
}

*Professora colaboradora no curso de graduação da Universidade Estadual de Santa Catarina (UDESC), mestre em Arquitetura e Urbanismo pelo Programa de Pós-Graduação em Arquitetura e Urbanismo (PósArq) da Universidade Federal de Santa Catarina (UFSC).

\section{Resumo}

O presente artigo tem como objetivo discutir as relações físicas e visuais estabelecidas e rompidas no aterro da Baía Sul, na cidade de Florianópolis, SC, a partir da sua construção e consolidação na década de 1970. Se estabelece uma discussão e reflexão teórica sobre conceitos como territórios, limites, bordas e eixos discutindo-os na área objeto de estudo do trabalho. Propõe-se ainda uma breve análise sobre as relações físicas e visuais entre os territórios determinados na área em estudo, buscando entender o significado da inserção de novos territórios, assim como sua identidade e as implicações das mudanças e inserção de novos limites. As discussões estabelecidas instigam a busca pela compreensão do que esses novos espaços urbanos significam e implicam na forma e na apropriação da cidade.

Palavras-chave: Território. Continuidade urbanas. Borda d’água.

\section{Abstract}

This paper aims to discuss the physical and visual relationships established and broken in the Baía Sul landfill, in Florianopolis SC, from its construction and consolidation the 1970s. Is establishes a discussion and theoretical reflection on concepts such as territories, limits, bordes and axes discussing them in the area object of study of the work. It also proposed a brief analyses on the physical and visual relations between the territories determined in the study area, searching to understand the meaning of the insertion of new boundaries. The discussion instigate the search for understanding what these new urban spaces mean and imply in the form and appropriation of the city.

Keywords: Territory. Urban continuity. Water's edge. 


\section{Os aterros como forma de expansão urbana}

procedimento de acrescentar área às cidades é uma técnica muito antiga, na Roma Imperial e na Grécia Antiga já existia esta prática. A técnica de moldar os terrenos conforme a necessidade humana desafiou desde muito tempo a engenharia a modificar a natureza. Esta prática de preenchimento de terra sobre o mar intensificou-se a partir do século XVII, aproximadamente. $\mathrm{Na}$ América do Norte, registros mostram que em Boston, nos EUA, no ano de 1640 , começou a ser comum a expansão das áreas de docas portuárias para ampliar a área da cidade que crescia muito devido ao intenso comércio e industrialização (PROCHNOW, et al, 2009). No Brasil, têm-se indícios que em Salvador e posteriormente no Rio de Janeiro, pequenos aterros começam a surgir no mesmo período. Assim como na cidade americana, o objetivo era a adequação dos espaços para áreas de atracadouro das embarcações. Com o passar dos anos, ambas as cidades utilizaram do mesmo recurso de expansão territorial com outras justificativas e objetivos. Estes aterros, ou aterros marítimos, são acúmulos de terra removidos para nivelar ou altear um terreno. Por meio destes é possível transpor terra ou outros sedimentos para uma área a fim de mo- dificar a configuração original.

Á partir do século XIX muitas outras cidades começam a utilizar esta técnica no limite de seus territórios, tanto em áreas de baías quanto de rios e a maior justificativa neste período, era a prática sanitarista vigente na época. As regiões de beira de rio eram zonas propícias para o desenvolvimento de doenças, onde se encontravam ruas mais estreitas e habitações mais precárias. Com isso, diversas cidades iniciam este período de modificações das áreas costeiras, que geralmente, além de construção de áreas de aterro, previam um conjunto de medidas e modificações na estrutura urbana. Com o crescimento excessivo e não planejado das cidades litorâneas, a estratégia de expansão dessas cidades em direção ao mar, por meio dos aterros marítimos, tornou-se uma prática recorrente em muitos países.

No Brasil, esta atividade se intensificou nas últimas décadas do século XX. Os aterros surgem, na maior parte dos casos, por conta de uma estratégia para a ampliação do sistema viário, predominando uma ideologia modernista. 
Esta prática marcou a transformação de cidades como Rio de Janeiro, Salvador, Porto Alegre, São Luís, Vitória, entre outras. Essas expansões modernas são, portanto, novos espaços nas cidades, articulando-se com coexistências da cidade antecedente a esses. A ocorrência desses aterros nas cidades modifica não só funções específicas de circulação, sanitárias e de lazer, como também modifica a paisagem desse lugar. Os aterros, realizados em diferentes contextos surgem ora como continuidade de tramas urbanas já existentes, ora como tábulas rasas - vazios - para se iniciar uma nova concepção dos espaços urbanos.

Em Florianópolis, a área hoje denominada de aterro da Baía Sul é resultado de um grande processo de expansão ocorrido na década de 1970 na área adjacente ao centro fundacional da cidade. $O$ que é interpretado como aterro da Baía Sul tem na sua formação outros pequenos aterros que foram executados desde o século XIX, ainda com a premissa de aformoseamento, ou adequações dos cais. $\mathrm{O}$ grande aterro da Baía Sul, área que avançou sobre a baía aproximadamente $600.000 \mathrm{~m}^{2}$, é decorrente de intenções do Plano Diretor Municipal de 1976 e de um Plano de Desenvolvimento Integrado para a Microrregião de Florianópolis. Entre muitas intenções político-econômicas que ocorreram decorrentes desses planos e refletiram nesse espaço da cidade (SUGAI, 2015), o aterro foi o mais significativo. O resultado que se caracterizou foi de um espaço de caráter rodoviarista, seguindo as premis sas do movimento moderno.

\section{Limites e bordas na área central de Florianó- polis}

Os acréscimos territoriais, por meio dos aterros, acabam por revelar no espaço urbano as diferenças dos tempos que os conformaram. A trama urbana, as edificações e mesmo as formas de apropriação revelam territórios diferentes e ainda características e memórias não mais presentes.

No caso do aterro da Baía Sul a contraposição dos espaços marcadas pela ausência de unidade que os diferentes tempos de inserção impuseram na trama urbana, apresenta também outro elemento urbano. As relações entre terra e mar existentes nas cidades revelam os limites, as bordas e as fronteiras do território. No caso dessa área central esses limites são representados pelas linhas da borda d’água, existentes ou modificadas.

Kevin Lynch (1997) define que as cidades, qualquer uma delas, possuem uma imagem pública, e que esta é a sobreposição de muitas imagens individuais. O conteúdo destas imagens comuns pode ser decomposto em cinco elementos essenciais: vias, limites, bairros, pontos nodais e marcos. Sobre os limites, o autor destaca que são fronteiras entre dois tipos de áreas, elementos lineares e "parecem mais fortes os limites que não só predominam visualmente, mas têm uma forma contínua e não podem ser 
1. HEIDEGGER, Martin. Poetry, Language, Thought. Nova York: Harper \& Row, 1971, p. 227.
Estes limites podem marcar uma ruptura natural quando diz respeito à própria geografia do território: um rio, o mar, uma falha geológica, o cume de uma montanha, ou uma falésia, por exemplo. Podem ser sociais, quando ocorrem por conta da ação humana: as segregações de classes refletidas em bairros distintos no território, a construção de um muro que separa um condomínio do restante da cidade; uma via marginal que delimita a ocupação e o zoneamento urbano, indicando aonde serão os espaços passíveis de ocupação e os espaços destinados somente à circulação de veículos. Estes limites podem ocorrer por elementos da paisagem também, decorrendo da própria morfologia da cidade: zoneamento mais ou menos permissivo em relação ao gabarito e uso do solo em áreas adjacentes; ou a tensão entre áreas antigas e históricas e novas áreas planejadas na cidade. Essa ruptura que se refere o autor é uma interrupção de certa continuidade, ou seja, não se trata de um elemento que não pertença aquele conjunto, mas que de alguma forma esse limite rompe (ou rompeu) com a unidade daquele espaço.

Conforme Heidegger (apud NORBERG-SCHULZ, $1_{1976)}{ }^{1}$, os limites na arquitetura são tratados também como fronteiras e entendidas não só por aquilo que encerra uma coisa, mas também como aquilo aonde algo começa a se fazer presente.

Norberg-Schulz compara as fronteiras de um espaço construído às fronteiras de uma paisagem:
As fronteiras de um espaço construído são o chão, a parede e o teto. As fronteiras de uma paisagem são estruturalmente semelhantes e consistem no solo, no horizonte e no céu. Essa similaridade estrutural simples tem importância fundamental para as relações entre os lugares naturais e os lugares feitos pelo homem. [...] Geralmente a fronteira, especialmente a parede, expõe a estrutura espacial como extensão, direção e ritmo contínuos ou descontínuos (NORBERGSCHULZ, 1976, p. 451, in NESBITT, 2008).

Conforme expõe Norberg-Schulz (2008), esses limites não têm sempre um caráter negativo. Estes são também parte da construção do espaço, e podem proporcionar suturas e articulações de um lugar, ideia também compartilhada por Lynch: "Enquanto a continuidade e a visibilidade são cruciais, os limites fortes não são necessariamente impenetráveis. Muitos limites são uma costura, muito mais que barreiras que isolam" (LYNCH, 1997, p. 71).

Nesse mesmo sentido, ao conceituar os limites dentro das lógicas do crescimento urbano, Panerai (2014) destaca que estes podem atuar por muito tempo como impedimento à expansão, e quando ultrapassados aparecem como ponto de partida de um crescimento oposto, materializando a diferença entre o tecido urbano anterior e aquele posterior. Ao interpretar esses limites no território, o autor ainda destaca que "como nenhuma situação é estável, a ser por um período determinado, um elemento pode fundar por desempenhar papéis sucessivos, transformando-se ao longo de um proces 
so completo de crescimento" (PANERAI, 2014, p. $67)$.

No caso da área em estudo, a Baía Sul que por muito tempo se caracterizou como um limite para a expansão da cidade, quando houve a necessidade e a possibilidade técnica essa fronteira foi superada, surgindo assim um crescimento oposto àquela da lógica existente na cidade.

O primeiro limite que contrapõe esses espaços é a linha da borda d água original, que se considera invisível por não existir fisicamente e se revela apenas na memória e nas oposições entre a forma urbana do território original e território introduzido. $\mathrm{E}$ o segundo limite, a linha da borda d'água atual, torna-se invisível por sua dificuldade de acesso e visualização no cotidiano da cidade. Essas linhas que configuram bordas d’água são espaços diferenciados que separam e distinguem diferentes áreas e assim, encerram ou iniciam um novo espaço.

Vistas a partir dos lugares que ficam encerrados ou separados pelas bordas, estas se percebem de um modo diferente: é o limite que marca a abertura ou fechamento para outro lugar distinto, dando lugar à experiência do atravessamento (ARROYO, 2007, online).

Essa colocação de Arroyo (2007) permite distinguir as bordas dos limites e fronteiras, no sentido em que a primeira possui a qualidade da experiência dessa transição, não podendo ser exatamente precisa. Enquanto o limite e a fronteira podem ser tratados fisicamente por possuírem elementos físicos ou naturais que permitem precisá-los no espaço.

As bordas no espaço urbano registram uma fenomenologia que é de ordem física e simbólica (ARROYO, 2007). A borda entre terra e mar, por exemplo, revela um encontro com a natureza, mas também carregam as histórias sociais e econômicas de formação de uma cidade. Podem significar dessa forma uma articulação entre dois espaços ou territórios, revelando assim um papel mediador entre as dualidades expostas de um lado e outro do limite, pertencendo a um ou a outro, ou a ambos, ocorrendo continuamente ou descontinuamente, criando assim espaços de transição e de intermediação. Este território de intermediação é consequência não somente de situações e transformações físicas, mas também de situações socioeconômicas. Portanto, estes limites, fronteiras e bordas são problematizados, pois incomodam na cidade e são, em alguns casos, ainda não resolvidos ora por se tratar de continuidade ora de ruptura.

No aterro da Baía Sul, em Florianópolis, a primeira borda d'água é a linha original que demarcava os limites entre terra e mar, antes do grande aterro introduzido, que na memória urbana representa a cidade portuária, dependente direta do mar. Nessa borda, as chegadas e saídas de barcos eram eventos que reuniam a população. Barcos trazendo mer- 

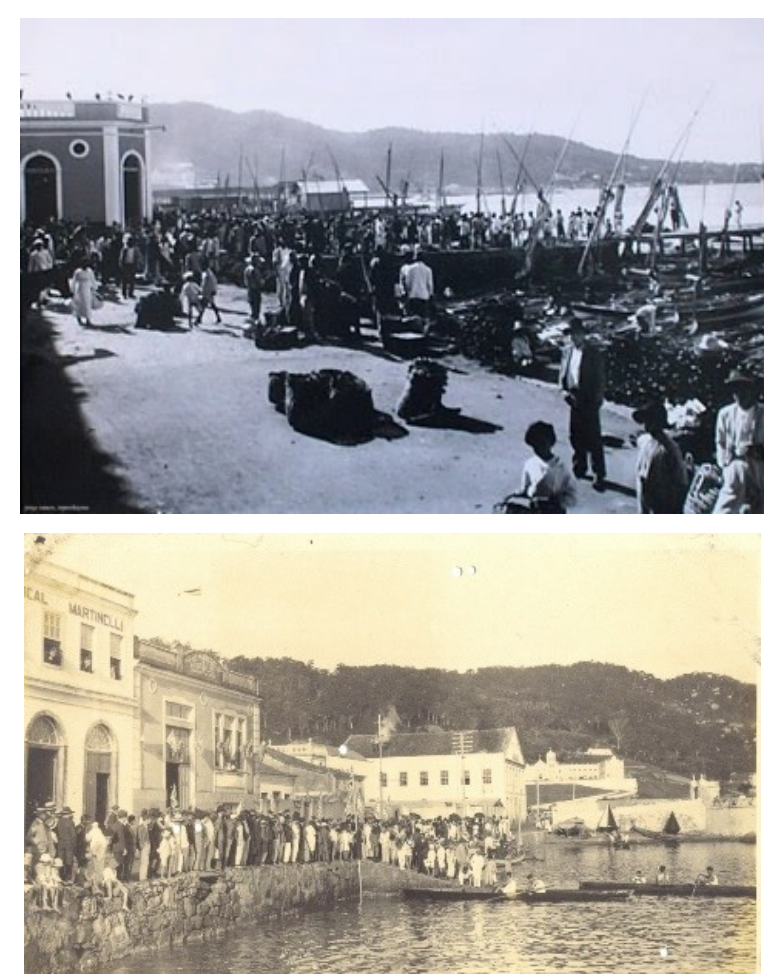

Figura 1: Dois momentos que mostram as relações estabelecidas na borda d' água antes do aterro: na praça do mercado com a chegada dos barcos de peixes, movimentação no estaleiro Arataca (1932), competição de remo na região da Prainha, próximo ao Forte da Santa Bárbara. Fonte: Acervo Casa da Memória. cadorias que descarregavam na praça do mercado; barcos trazendo aqueles que vinham para ficar e levando aqueles que partiam; barcos e navios que atracavam para fazer manutenções no estaleiro insular; e barcos, na verdade remos, que com o tempo passaram a fazer parte do cotidiano desta borda com o lazer da prática do remo. A cidade até início do século $X X$ não tinha nenhuma outra ligação com o continente e por isso todas as atividades estavam diretamente ligadas ao mar.

Efetivamente, naquele tempo, existia uma borda que se relacionava com as águas. As áreas nos limites da água se configuravam como ruas, praças ou mesmo trapiches aonde acontecia essa reunião de pessoas, como se observa em algumas imagens da época (FIGURA 1). Essa relação não se limitava a uma linha precisa entre terra e mar, mas sim a uma área de influência dessa baía e das atividades que se relacionam a esta.

Atualmente, esta borda d’água, não mais visível, é exatamente uma linha, que nos aspectos morfológicos se revela como oposição de dois tempos da cidade que se configuram no espaço. Não existem elementos que indiquem esse antigo limite, apenas a memória e alguns poucos vestígios que permitem relacionar a esta antiga maritimidade.

Assim, uma das formas de refletir também sobre essa borda d’água é em relação aos equipamentos e elementos que dela dependiam. As funções portuárias nessa área da cidade, mesmo antes da construção do aterro já apontavam enfraquecimento. Desde o início do século XX, as funções portuárias na Baía Sul já não apresentavam condições técnicas favoráveis aos calados mais profundos das novas embarcações (PELUSO JÚNIOR, 1991) e a construção da Ponte Hercílio Luz, em 1926, contribuiu para a reversão da prioridade no transporte marítimo. O próprio Plano Diretor da cidade, estabelecido em 1952, evidenciava este fato ao prever ao invés de diversos pequenos trapiches na região insular, um grande porto na região continental. O plano destacava outras potencialidades que surgiam na cidade, como a cidade universitária, que mesmo sem ter sido implantada no local previsto pelo Plano Diretor mostrava outros eixos de crescimento da cidade. Dessa forma as modificações de ordem social e econômica começam e ordenar as transformações da forma física da cidade, muitas das quais refletiram nessa borda.

Antes mesmo disso, no final do século XIX, com a implantação da República em 1889, esse enfraquecimento começou a ocorrer, conforme destaca Ferreira (1998, p. 47):

A implantação da República coincidiu com uma crise econômica bastante grande na llha de Santa Catarina. A economia, baseada na exportação de produtos agrícolas, sobretudo farinha de mandioca, encontrava-se enfraquecida. Outros pólos produtores surgiram do Estado em decorrência da colonização estrangeira. $O$ porto tivera seu movimento drasticamente reduzido. Eram estas 


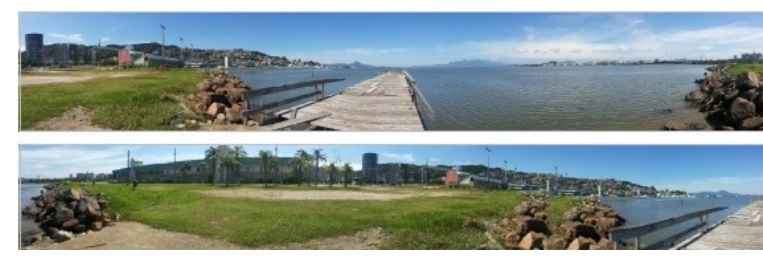

Figura 2: Imagens panorâmicas na atual linha d’água Figura superior, vista para o território água e figura inferior vista para o aterro. Fonte: Acervo do autor. (2017)

2. Em relação a estas dinâmicas sócio espaciais na grande Florianópolis, Sugai (2015), explica de forma rica e precisa no livro "Segregação silenciosa: investimentos públicos e dinâmica socioespacial na área conurbada de Florianópolis (1970-2000)".

usjt • arq.urb • número 27 | janeiro - abril de 2020 atividades que representavam as possibilidades de acumulação de riqueza e status, bem como a ocupação de cargos na Província do Império.

Mesmo as funções fabris da cidade que se relacionavam e dependiam do porto, aos poucos se deslocaram para a área continental. O crescimento populacional e os investimentos na cidade começaram a ordenar que as camadas de alta renda permanecessem na região insular e aquelas de baixa renda bem como as atividades não tão nobres se deslocassem da área central. Dessa forma, atividades industriais optaram por se dirigir as regiões continentais aonde o custo da terra era mais bai$\mathrm{xo}^{2}$, como é o caso da Fábrica de Rendas e Bordados Hoepcke (SUGAI, 2015).

Dessa forma, as mudanças ocasionadas pelo aterro e que transferiram a linha da borda d’água nesta área central, salientam as dinâmicas ocorridas nos centros urbanos e as transformações naturais nas cidades. Assim como coloca Teixeira (2002) ao descrevê-la como lugar de valor no centro histórico "a orla marítima se reveste dessa especificidade: ela desenha um duplo papel, o de chegada ao território colonizado e o de saída, rumo a metrópole" (TEIXEIRA, 2002, p. 57). Essa linha invisível, portanto, assim como outras tantas linhas históricas, demarca momentos, situações e os tempos da cidade, e nesse caso específico refletem ainda as distinções na forma urbana. No entanto, resgatá-la não significa retomar todas as qualidades e atividades existentes quando esta era ainda visível.
A segunda borda d’água, o atual limite entre terra e mar, representa hoje exatamente este limite, uma linha física e precisa. Por não possuir atividades frequentes que qualifiquem ou mesmo permita uma relação visual direta que poderia representar uma articulação entre as diferentes polaridades - terra e mar -, esse limite atual não exerce uma influência de borda de água e das características decorrentes desta.

\section{Territórios na área central de Florianópolis}

Esses limites e bordas do espaço acabam por definir muito mais que barreiras que devem ser superadas ou mantidas, estas representam também momentos que a cidade definiu na sua história e se materializam no traçado urbano. Nesse sentido, na área do aterro da Baía Sul, estas revelam diferentes formas e diferentes territórios numa mesma região da cidade.

Um território é o produto de toda uma história natural e humana, e as condições do desenvolvimento, em particular os conflitos que o agitarão, decorrerão dessa história. [...]. Esse quadro patrimonial compreende a paisagem, os fatores favoráveis ou desfavoráveis à vida dos homens e às suas atividades linguagem, as crenças, os ritmos da vida cotidiana, a relação tradicional com os territórios vizinhos e as entidades de nível inferior e de nível superior, sociais e econômicas. Compreende também a hierárquica e administrativamente (VARINE, 2013, p. 19). 
3. HAESBAERT, Rogerio. O mito da desterritorialização: do "fim dos territórios" à multiterritorialidade. Rio de Janeiro: Bertrand Brasil, 2004, p. 395
No entendimento do autor, o território definido por componentes patrimoniais, está relacionado às ações naturais e sociais e são geradores de raízes e identidade. Ou seja, a identidade sociocultural está ligada aos atributos do espaço concreto do território: a natureza, o patrimônio arquitetônico e a paisagem. Dessa forma, os grupos sociais não podem ser compreendidos sem o seu território. Nesse sentimento, a essência do termo território ocorre pelo seu significado de permanências físicas e sociais. Ao expor o termo território em suas pesquisas acerca dos patrimônios nos territórios, Varine afirma que este conceito é "essencialmente intelectual, ou mesmo tecnocrática e político" (VARINE, 2013, p. 186). Não deixa de ser verdade, pois o conceito amplo, mesmo na sua disciplina de origem, a geografia, tem uma abordagem bastante racional.

É recorrente o entendimento de território como a noção de Estado-Nação, no sentido em que o território era associado aos limites físicos do poder de ação de determinado Estado. Nessa concepção, o território enquanto campo de forças é entendido como um espaço delimitado por e a partir das relações de poder, sendo essencialmente um exercício de poder (SANTOS, 2006). Nesse sentido Santos (2006) deixa claro que essa era uma visão herdada da Modernidade e a Pós Modernidade já entende o território na sua forma mais transnacional Sendo assim, a ideia contemporânea de território não se restringe aos limites de Estado concebidos, esses podem ocorrer em diversas escalas e com limites flutuantes: podem ser construídos e desconstruídos, representados dentro de distintas escalas temporais e ainda podem apresentar caráter permanente ou temporário.

Abrindo essa perspectiva na concepção espaçotemporal do território, a geografia política contemporânea propõe uma classificação de quatro concepções diferentes para o termo: a primeira delas política ou jurídico político, aonde se refere às ações de espaço-poder (a visão moderna apresentada); a segunda, conforme Haesbaert (apud FILHO, 2013, p. $46)^{3}$, cultural ou simbólico-cultural "em que o território é entendido como produto da apropriação/valorização simbólica e subjetiva de um grupo em relação ao seu espaço vivido"; econômica: sendo esta a concepção do território como relação capital-trabalho; e a última delas naturalista: fundada na relação natural do homem com seu meio físico. Dentre essas concepções, a ideia comum entre elas é a relação do homem com o espaço natural. Ou seja, o território é, em qualquer uma de suas classificações, entendido como resultado de ação social que, de forma concreta e abstrata se apropria de um espaço físico e simbólico. Segundo essa visão, o território aparece como resultado de relações sociais, e estas não necessariamente são definidas pelas fronteiras claras dos territórios político-administrativos. Por serem frutos das ações humanas, estas podem criar suas próprias fronteiras com base em suas identidades e relações histó- 
4. RONCAYOLO, Marcel. La ville et ses territoires. Paris: Ed. Gallimard, 1993, p. 288.

5. Meyer (2006) utiliza o termo "peça urbana" para descrever um "trecho de cidade no qual se estabelece um perímetro que será objeto de análise e projeto urbano." rico-culturais.

A cidade como um "território que organiza territórios", segundo Roncayolo (apud Meyer, 2006) ${ }^{4}$, nos permite "analisar e apreender os aspectos espaciais e funcionais do território" e assim, elaborar critérios para perímetros homogêneos. Segundo Meyer (2006), as novas questões estabelecidas pelo urbanismo pós Movimento Moderno, por volta da década de 1960, exigiram uma revisão dos métodos de análise e de projeto. Entre essas questões, a conceituação dos territórios.

A autora destaca que para o urbanismo contemporâneo tratar dos territórios hoje, frente aos tantos conceitos do termo que se intensificaram a partir dos anos 1980, nos permite entendê-lo como a chave a reorganização da própria cidade. Ou seja, todos os conceitos que surgiram antes "apontam para novas dinâmicas que coincidem com o enfraquecimento da cidade compacta" (MEYER, 2006, p. 40), traduzindo os diversos processos que devem ser estudados, como os fenômenos econômicos, sociais, políticos administrativos etc. Dessa forma o território para a autora, parte da necessidade de trabalhar em novas escalas, e por nova escala entende-se:

A busca de parâmetros que definam os limites físicos, as fronteiras funcionais, as barreiras de todo tipo, o sentido transitório de um espaço, enfim tudo aquilo que demarca ao tempo as

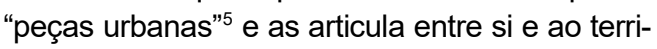

tório que as contém. (MEYER, 2006, p. 40)

Essa breve conceituação do termo, enfatiza o que a análise urbana, realizada por Ferraro (2017) nos demonstra em relação ao aterro da Baía Sul e seu entorno imediato, em que as distinções da malha urbana organizam diferentes territórios nesse mesmo território que é a área central da cidade. A leitura dessa peça urbana compreendida entre a cabeceira insular da Ponte Hercílio Luz e o Hospital de Caridade, por meio das redes de vias, dos parcelamentos fundiários e das edificações nos revela a formação de distintos territórios: território novo, território antigo e território água.

O território do aterro da Baía Sul, revela o território novo, introduzido. Um perímetro demarcado pela antiga linha da borda d’água do mar e a atual linha d’água, onde a sua homogeneidade é identificada pelos ideais modernistas refletidos neste espaço: vias expressas que interceptam toda a extensão deste território, parcelamento viário expressivo e edificações isoladas que não se relacionam entre si. O território original é evidenciado também pela forma urbana. Este reflete o tempo de fundação e expansão da cidade dentro dos seus limites naturais. Possui sistema viário que atende à veículos e pedestres, lotes predominantemente regulares e definidos e edificações que se relacionam tanto com as edificações vizinhas quanto com a própria rua. O limite entre esses territórios representado pela antiga linha da borda d’água não é mais visível no meio 


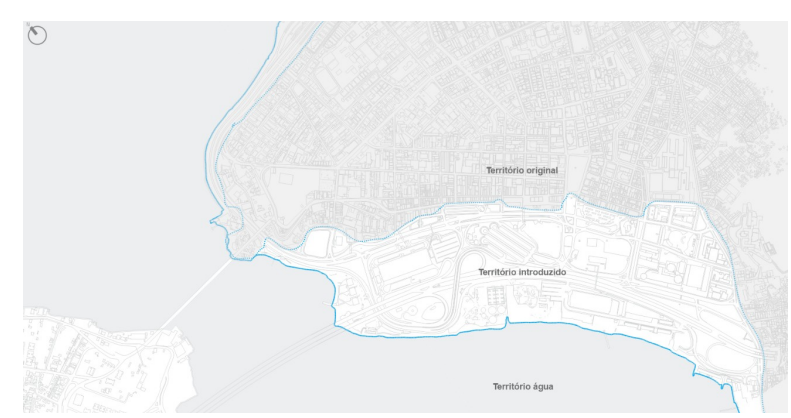

Figura 3: Planta esquemática demostrando os três territórios que se configuram na área central de Florianópolis, diferenciados pelo tecido urbano e suas apropriações. Mapa sem es cala. Fonte: Elaborado pelo autor (2017) a partir de mapa base em formato .dwg fornecido pelo curso de Arquitetura e Urbanismo (UFSC) urbano. São vestígios na arquitetura das edificações, e em pequenos elementos urbanos, que indicam que houve uma mudança no território, no entanto, não deixam explícito essa modificação. A maior evidencia desse limite está na memória urbana, daqueles que vivenciaram o tempo do avanço e surgimento desse novo território, e no crescimento oposto que foi materializado neste espaço.

O último território que se revela nessa peça urbana é o território água, o qual sofreu com todas as modificações ocorridas nos demais. Com sua alteração, o limite entre a terra e o mar não significou somente a alteração da forma física dos espaços que o antecedem, mas também mudanças na forma como este se relaciona atualmente com a cidade. As edificações próximas não se relacionam mais diretamente com este território, pois possuem outras funções que não relacionadas às águas. Com isso e com a forma como estas foram implantadas, a população não se utiliza mais desta borda d'água, revelando essa como um limite invisível.

Dessa forma, esses territórios são identificados e se distinguem por apresentar uma ruptura no espaço. Ou seja, existe uma descontinuidade da unidade do espaço e nessa área, esta é refletida por

meio da forma urbana. Esses distintos territórios são separados por limites invisíveis, mas que se revelam nas diferenças imbricadas na forma física dos territórios. Estes não devem ser interpretados com um caráter negativo, pois evidenciam justamente as mudanças dos diferentes tempos.

\section{Sobre relações físicas e visuais no aterro da Baía Sul}

Essas constatações sobre os diferentes territórios que se configuram com a construção do aterro, assim como o entendimento do processo de construção dessa área da cidade, faz refletir sobre as modificações referentes a maritimidade dessa área central. É evidente que a expansão do território não preservou as mesmas qualidades anteriores, no entanto, possibilitou outras. No caso do aterro da Baía Sul, ainda que já nas primeiras constatações observa-se que a água já não cumpra o mesmo papel, como antes da construção do aterro, investigou-se essa relação, possibilitando inclusive outras formas de interpretar a área do aterro.

Os territórios introduzidos nas cidades, fruto da atividade de aterramento marítimo podem representar uma nova lógica para o crescimento e expansão do espaço urbano. Atualmente, alguns estudos em cidades de água que sofreram com as expansões territoriais por meio dessa prática de aterros, como Lisboa e Barcelona, nos revelam que para a valorização das frentes de água, ou as bordas d’água, deveexistir uma articulação territorial desde o interior da cidade. 
Pensar a articulação significará que, para além de uma frente de água requalificada há que integrá-la física e visualmente no interior da cidade, tirando partido deste território mesmo em áreas mais distantes (CASTRO, 2011, p. 280).

Ana Rita Martins Ochoa de Castro (2011), em sua tese de doutorado, reforça ainda que "o usufruto da frente de água não implica necessariamente um acesso físico e pode também passar pela visualização da frente de água" (CASTRO, 2011, p. 274). Com isso, fica claro que para o real entendimento do território do aterro e da frente de água pertencente a este, deve-se interpretar as suas adjacências, que neste caso são reveladas como o território antigo, do centro fundacional e o território água, a Baía Sul, protagonista e coadjuvante das transformações ocorridas.

Tanto na cidade portuguesa quanto na cidade espanhola, os aterros construídos, anteriores ao aterro da Baía Sul, modificaram também a lógica dessas estruturas urbanas, proporcionando pouco contato com o mar e direcionando a malha urbana para o seu interior. No entanto, em cada uma das cidades alguma particularidade em relação à integração entre esses territórios (original $X$ introduzido $X$ água) foi alcançada com o desenvolvimento da cidade. Conforme a autora concluiu em seu trabaIho, ainda que com malhas urbanas bastante distintas, ambas as cidades possuem na estrutura elementos que articulam os distintos territórios, terra e água. E ainda, que uma maior diversidade de malhas urbanas corresponde uma maior diversidade morfológica nas estruturas de articulação. Essas articulações, que denominamos de relações, são as formas como os três territórios - território original, território introduzido (aterro) e território água - podem se relacionar entre si, segundo algumas categorias de análise, e destacamos as relações físicas e visuais.

As relações físicas são os aspectos de conformação do território, em que são consideradas as possibilidades de se transpor fisicamente de um território ao outro, considerando desde o seu interior. Enquanto as relações visuais consideram a possibilidade de visualização de todos os territórios. Ou seja, desde o seu interior, no território original, até onde é possível perceber o território seguinte, seja este $o$ aterro ou a água.

Sobre essas relações com a água no contexto urbano, Castro (2011) determina alguns elementos e fatores dessa articulação. No sentido físico, a autora busca entender como ocorre no traçado da cidade essa interação à frente de água buscando a lógica dos subsistemas de estruturas urbanas que se articulam com a frente de água, ou seja, o comportamento do tecido urbano em relação à orla marítima. E no que diz respeito à tores dependem essa visualização. Esse fator detém uma importância decisiva nas qualidades visuais do espaço. Do ponto de vista morfológico, é possível identificar dois tipos de estrutura de conexões visuais: em linha reta e sinuo- 
sa. A primeira propicia uma visualização constante na frente de água e a segunda proporciona uma descoberta progressiva e fracionada da frente de água (OCHOA, 2014):

A forma dessas estruturas, mas também a sua extensão e continuidade definem um determinado tipo de prolongamento da frente de água para o interior do território. Por sua vez, o conjunto dessas mesmas estruturas assume, em cada cidade, um determinado grau de prolongamento da água para o interior do território. Porém, no seguimento dos anteriores raciocínios, este prolongamento da frente de água para o interior do território terá também que considerar a perspectiva visual, para além da física (OCHOA, 2014, p. 49).

A análise da conjunção dos dois fatores, físico e visual possibilita a compreensão de como a frente de água é exportada para o interior da cidade (CASTRO, 2011) e nesse caso nos auxilia na compreensão das relações de maritimidade que permanecem ou que se perderam nos territórios de Florianópolis e resulta como uma forma de intepretação da continuidade entre os limites territoriais revelados.

\section{Eixos e linhas de força no aterro da Baía Sul}

As relações físicas entre os territórios são interpretadas pelas relações que estes mantem uns com

os outros e são apreendidas pelos espaços públicos que permitem a transposição entre esses. No caso dos aterros, território antigo e território introduzido (aterro) essas conexões podem ocorrer pela presença de eixos entre um e o outro, indicando uma forma de relação e continuidade entre eles. Segundo Capel (2002), os eixos na forma urbana tendem a atuar como marcos morfológicos que condicionam as gêneses e o crescimento das formas subsequentes, e sobre estes ainda acrescenta:

As investigações de geógrafos e arquitetos tem mostram que as formas fundamentais do plano que tem maior significado funcional são as ruas, e especialmente aqueles eixos básicos que unem polaridades destacadas no tecido urbano (CAPEL, 2002, p. 70, tradução nossa).

Segundo o Dictionnaire d'urbanisme et de l'aménagement, de 1988, o conceito de eixo está associado ao desenvolvimento urbano (axe de développement), e estes como uma forma de crescimento das cidades e que possibilita a heterogeneidade do traçado urbano (MERLIN, et al, 1988). Gordon Cullen (2009, p. 113) trata esses eixos como linhas de forças do território:

A função essencial de uma cidade deve tornar-se evidente, após uma simples vista de olhos pela planta. Isto resulta obviamente porque a organização obviamente porque a organização dos seus elementos reflete certas linhas de força que representam igualmente uma combinação de circunstâncias que estiverem na origem da cidade. [...] Esta oportunidade surge mais facilmente em relação à cidade, por exemplo, uma cidade tipicamente marítima, em que as linhas de força têm 


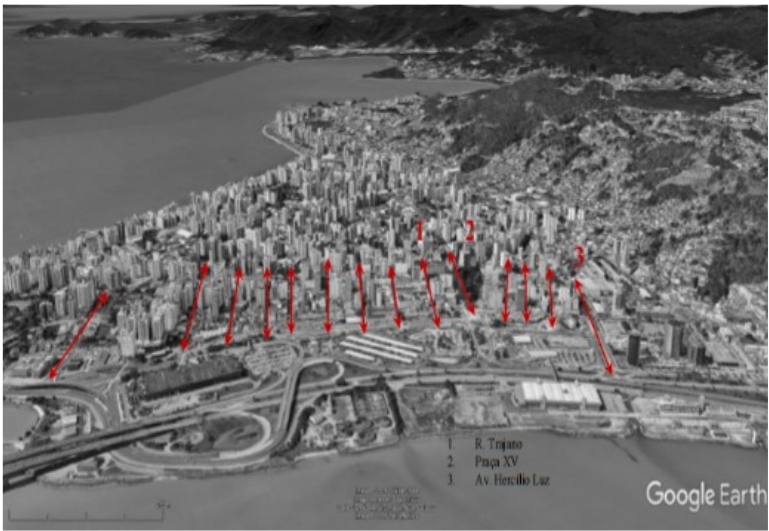

Figura 4: Imagem aérea da área do aterro da Baía Sul e a cidade fundacional. Não se observa a continuidade das linhas de força do território tradicional no território do aterro. Fonte: Google Earth. Capturado em março de 2017 e adaptado pelo autor.

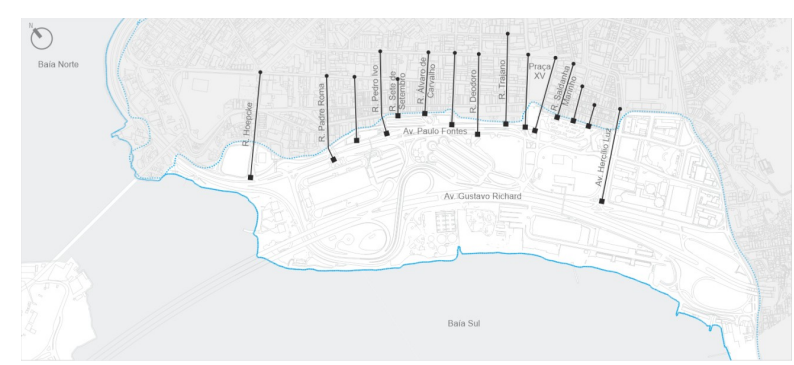

Figura 5: Mapa esquemático com relações físicas entre os territórios. Mapa sem escala. Fonte: Elaborado pelo autor (2017) a partir de mapa base em formato .dwg fornecido pelo curso de Arquitetura e Urbanismo (UFSC). uma relação óbvia e imediata com as linhas de demarcação no sentido geográfico. A verdadeira raison d'être (razão de ser) da cidade costeira é a linha ao longo da qual se encontram terra e água, e isso explicará talvez que nas cidades costeiras a personalidade resista melhor do que em quaisquer outras.

Em Florianópolis, o crescimento sobre o mar, seguindo uma nova ideologia de expansão, não significou a continuidade dos eixos existentes sobre $o$ aterro. Pelo contrário, esse seguimento no novo território, é percebido de forma sutil e pontual em apenas alguns eixos da trama urbana, e não se apresenta como uma clara intenção no desenho urbano. Contrariando a colocação de Cullen (2009) que diz que as cidades marítimas teriam essa facilidade em explorar suas linhas de força observa-se que quando ocorrido o aterro da Baía Sul, esses eixos potenciais não foram mantidos. Mais que isso, não existe a manutenção da sua razão de ser litorânea.

No caso da relação entre o território introduzido e o território água, essas conexões podem ocorrer também pela existência de eixos, que integram desde o interior do território até a água, ou pela presença de espaços livres públicos ao longo desse limite, que permitam esse acesso e relação efetiva entre os territórios. No entanto, no aterro da Baía Sul não ocorre nenhuma forma de conexão física direta desde o interior do território fundacional até a água. A representação destes eixos (figura 4) permite perceber que as linhas de força, representadas pelos eixos de vias da malha urbana, desde o interior do território original, não possuem relação com o território água. $\mathrm{E}$ em relação à articulação com o território aterrado, estas se articulam em diferentes graus, alguns avançam mais ou menos em extensão o aterro, mas nenhuma o intercepta por completo.

No que diz respeito às relações físicas estabelecidas entre os territórios, estas são representadas na Figura 5, demarcando a partir de determinado ponto no território original, até onde é possível percorrer a pé aquele eixo.

No aterro da Baía Sul e suas adjacências, a grande maioria, se integram até no máximo a primeira avenida, Av. Paulo Fontes, que intercepta o aterro. E esta integração direciona até os equipamentos urbanos localizados na primeira zona de parcelamento. Apenas um eixo, da Avenida Hercílio Luz, prolonga-se um pouco mais, interrompendo-se na avenida Gustavo Richard, aproximadamente no ponto médio do aterro, e um pouco mais próximo ao limite da água. Este esquema reforça que no traçado do aterro não se considerou, desde a sua idealização e mesmo com as pequenas alterações sofridas, uma continuidade nas estruturas urbanas existente e naquelas projetadas na nova área. Posto dessa forma, o desenho imbricado no aterro mostra também que as linhas de força presentes no território anterior, não tiveram continuidade na trama urbana, perden- 


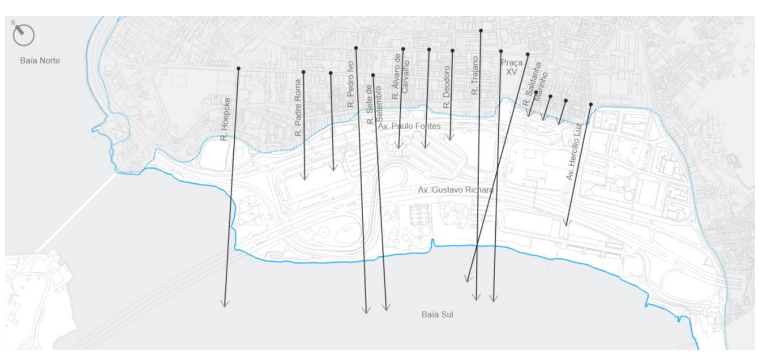

Figura 6: Mapa esquemático com relações visuais entre os territórios. Mapa sem escala. Fonte: Elaborado pela autora (2017) a partir de mapa base em formato .dwg fornecido pelo curso de Arquitetura e Urbanismo (UFSC). do assim sua forma na transposição entre os territórios. Além disso, a grande linha de força que se revela neste projeto são as duas novas avenidas criadas, Avenida Gustavo Richard e Avenida Paulo Fontes, ou seja, linhas de força transversais que acabam por atuar como bloqueio dessa transposição (FERRARO, 2017).

Fisicamente, as relações com o território água também não ocorrem. Os espaços que permitem o acesso às frentes de água são públicos, mas difíceis de acesso por conta de barreiras pontuais e falta de integração com a malha como um todo. Nenhum dos eixos relaciona fisicamente os três territórios, ou seja, não se tem uma relação contínua entre o centro fundacional, o aterro e o mar. Interpreta-se também, a partir dessa análise que o posicionamento das edificações influencia nessas possibilidades de continuidade dos percursos. Assim como observa Castro (2011),

Um posicionamento paralelo ao eixo agregador confere uma dinâmica diferente de um posicionamento perpendicular. Por outro lado, um posicionamento regular da edificação configura uma determinada cadência ao espaço urbano, ao contrário das situações em que a edificação aparece sem uma regra definida (CASTRO, 2011, p. 196).

Essa análise das relações físicas entre os territórios evidencia como a trama urbana da cidade tradicional e do aterro não são homogêneas, dificultan do assim as conexões e continuidades entre os distintos momentos históricos. Da mesma maneira que revela como as grandes avenidas construídas sobre o aterro tornam-se barreiras físicas, dificultando a transposição delas e consequentemente impactando nas relações de continuidade que poderiam ocorrer entre o aterro e a água e o território original e esta.

Enquanto sobre as relações visuais estabelecidas (Figura 6), percebe-se que as maiores relações ocorrem onde a topografia favorece um visual mais distante. Nas ruas sem a topografia acentuada, o ponto máximo de visualização concentra-se no aterro. Ou seja, o ponto focal no trajeto, concentra-se em algum elemento específico instalado no território novo ou é possível apreender parte do conjunto sobre este. Outros eixos específicos, como ao Eixo da Rua Hoepcke, da Rua Padre Roma, da rua Trajano e da Praça XV, permitem uma apreensão, em determinados pontos do trajeto, do território do aterro e do território água. Essas situações visuais pontuais ocorrem não intencionalmente.

Ainda que os eixos direcionem para uma valorização de determinados elementos, como é o caso do eixo da rua Padre Roma e da rua que possuem em seu ponto focal o edifício da Rodoviária, estes não são marcados ou mais bem revelados na cidade por inúmeros outros elementos envolvidos que acabam por não fortalecer esse visual. O esquema analisado também permite identificar o tipo de estrutura, 


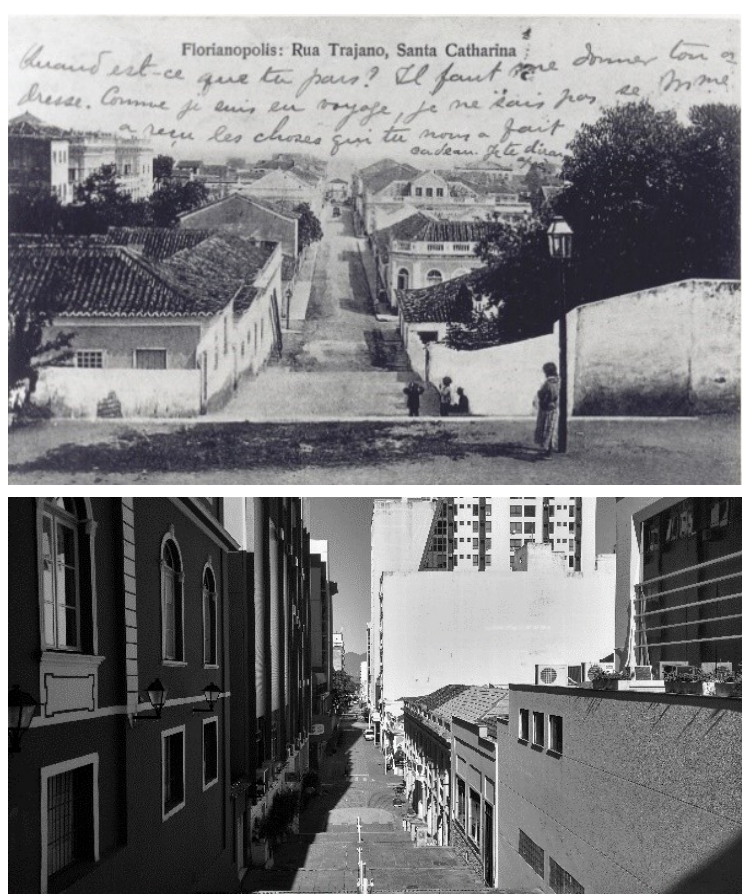

Figura 7: Eixo da Rua Trajano, no século XIX e em 2017 Fonte: Acervo da Casa da Memória e Acervo pessoal do autor. segundo Ochoa (2014) como uma conexão em linha reta, fato que pode proporcionar uma visualização constante com os territórios mais distantes. Por conta da largura de determinadas vias, da topografia, ou mesmo de elementos (edifícios) urbanos que atuam como bloqueios visuais, nem sempre essa visualização mais distante permite perceber o território água, conforme observado também na figura 7 .

Com isso, percebe-se que por mais que as relações físicas não sejam diretamente possíveis, em situações pontuais tanto o território novo do aterro quanto o território água, podem ser valorizados. 0 Eixo da Rua Trajano (Figura 7), por exemplo, sintetiza muitas dessas apreensões contemporâneas e as modificações dessas relações com a inserção do aterro. Visto do mesmo ponto no século XIX e hoje tanto a configuração da paisagem, quanto as relações que se estabelecia por meio desse eixo se transformaram consideravelmente.

Desta breve análise, ressalta-se as relações que um território deve estabelecer com os diversos tempos de construção e a importância da água na cidade, onde não é preciso ter acesso físico a esta para usufruir de suas qualidades no meio urbano. Com isso, a visualização desta é de extrema importância no espaço urbano, pois além das qualidades diretas que acrescenta, esta como se pode comprovar ao longo dos tempos, "desempenha um papel fundamental na imagem das cidades" (CAS
TRO, 2011, p. 281).

\section{Considerações Finais}

O estudo possibilitou algumas considerações sobre esta área, e possibilita ainda diversos aprofundamentos e continuidades de pesquisas. A primeira delas em relação ao processo de análise da área. Para futuros trabalhos e intervenções na área em estudo deve-se analisar extrapolando o território introduzido (aterro) e relacioná-lo aos territórios adjacentes, além das reflexões históricas e teóricas sobre a identidade desse lugar. Ainda, com as discussões desenvolvidas pode-se interpretar que em relação a sua identidade e pertencimento, atualmente, o território do aterro pertence a terra e ao mar e ao mesmo tempo não pertence a nenhum desses. Sua lógica de inserção não se tornou homogênea à área precedente e não valorizou o principal caráter da área, sua relação com as águas da Baía. Justamente essa ausência de homogeneidade, revela limites entre esses territórios, que são representados pelas distintas formas.

As formas de integração, física e visual, entre esses distintos espaços territoriais revelados, no caso do aterro da Baía Sul não ocorrem de forma intensa e marcante em nenhum dos aspectos. Isso ocasiona a ausência de coesão entre os territórios, fortalecendo a identidade predominante do território sica da cidade, mas também o modo de tratar os limites entre terra e mar em cada período da cidade, representado nos diferentes territórios. 


\section{Referências}

ARROYO, Julio. Bordas e espaço público: Fronteiras internas na cidade contemporânea. Revista Arquitextos, São Paulo, ano 07, n. 081.02, Vitruvius, fev. 2007. Disponível em: <http://www.vitruvius.com.br/revistas/read/arquitextos/07.081/269>. Acesso em: 13 jan. 2020.

CAPEL, Horacio. La morfología de las ciudades I. Sociedad, cultura y paisaje urbano. Barcelona: Ediciones del Serbal, 2002.

CASTRO, Ana Rita Martins Ochoa de. Cidades e Frentes de água: Papel articulador do Espaço Público. Tese (Doutorado) - Programa de Pós Graduação em Arquitetura da Faculdade de Belas Artes. Universidade de Barcelona. Barcelona, 2011.

CULLEN, Gordon. Paisagem Urbana. Lisboa: Edições 70, 2009.

FERRARO, Luiza Helena. Entre terra e mar: Aspectos morfológicos e patrimoniais do aterro da Baía Sul. Florianópolis (SC). Dissertação (Mestrado) - Programa de Pós-Graduação em Arquitetura e Urbanismo. Universidade Federal de Santa Catarina. Florianópolis, 2017.

FERREIRA, Sérgio Luiz. O Banho de Mar na llha de Santa Catarina. Florianópolis: Editora das Águas, 1998.
FILHO, João Bosco Moura Tonucci. Espaço e território: um debate em torno de conceitos-chave para a geografia crítica. Revista Espinhaço | UFVJM, Diamantina, ano 2, v. 1. p. 41-50, jun 2013.Disponível em: http://www.revistaespinhaco.com/index.php/ journal/article/view/16. Acesso em: 13 jan. 2020.

LYNCH, Kevin. A imagem da cidade. São Paulo: Martins Fontes, 1997.

MERLIN, Pierre; CHOAY, Françoise. Dictionnaire de l'urbanisme et de l'aménagement. Paris: PUF, 1988.

MEYER, Regina Maria Prosperi. O urbanismo: entre a cidade e o território. Revista Ciência e Cultura, São Paulo, v. 58, n. 1, p. 38-41, jan/mar 2006. Disponível em: http://cienciaecultura.bvs.br/scielo.php? script=sci_arttext\&pid=S0009-67252006000100016.

Acesso em: 13 jan. 2020.

NORBERG-SCHULZ, Christian. O fenômeno do lugar (1976). In: NESBITT, Kate (org), Uma nova agenda para a arquitetura: antologia teórica (1965-1995). São Paulo: Cosac Naify, 2008, p 443473.

OCHOA, Rita. Cidades e frente de água: ligações físicas, visuais e simbólicas. Revista Online do Museu de Lanifícios da Universidade da Beira Interior, Covilhã, n. 03, p.43-58, maio 2014 Disponível em: <http://www.ubimuseum.ubi.pt/n03/_edit/ 
ubimuseum03-print-folder/ubimuseum.03.pdf>. Acesso em: 13 jan. 2020.

PANERAI, Philipe. Análise Urbana. Brasília: Editora Universidade de Brasília, 2014.

PELUSO JÚNIOR, Victor Antônio. Estudos de geografia urbana de Santa Catarina. Florianópolis. Editora da UFSC. 1991

PROCHNOW, Ronan Max, SANTO, Mariane Alves Dal, e AMEY, Robert. A expansão das cidades sobre a Zona Costeira: Estudo de Caso de Florianópolis, BR, e Boston, USA. In $12^{\circ}$ ENCONTRO DE GEÓGRAFOS DA AMÉRICA LATINA. Montevidéu, 3-7 de Abril de 2009. Disponível em: http:// www.geolab.faed.udesc.br/publicacoes/ Artigos Egal/Prochnow Egal.pdf. Acesso em: 13 jan. 2020.
SANTOS, Milton. A natureza do espaço: técnica e tempo . São Paulo: Universidade de São Paulo, 2006.

SUGAI, Maria Inês. Segregação Silenciosa: Investimentos públicos e dinâmicas socioespacial na Área conurbada de Florianópolis (1979-2000). Florianópolis: Editora da UFSC, 2015.

TEIXEIRA, Luiz Eduardo Fontoura. Espaços públicos na orla marítima do centro histórico de Florianópolis: o lugar do mercado. Dissertação (Mestrado) - Programa de Pós Graduação em Geografia. Universidade Federal de Santa Catarina. Florianópolis, 2002.

VARINE, Hugues de. As raízes do futuro: o patrimônio a serviço do desenvolvimento social. Porto Alegre: Medianiz, 2013.terreiro de candomblé em São Paulo". In: Comunicações do Iser: Rio de Janeiro, v. 41, 1991. 